\title{
An analysis of the utilisation of chemoprophylaxis against Pneumocystis jirovecii pneumonia in patients with malignancy receiving corticosteroid therapy at a cancer hospital
}

\author{
LJ Worth ${ }^{*, 1,2}$, MJ Dooley ${ }^{3,4}$, JF Seymour ${ }^{2}$, L Mileshkin ${ }^{2}$, MA Slavin ${ }^{1,2}$ and KA Thursky ${ }^{1,2}$ \\ 'Victorian Infectious Diseases Service, Centre for Clinical Research Excellence in Infectious Diseases, Grattan Street, Parkville, Victoria 3050, Australia; \\ ${ }^{2}$ Department of Haematology \& Medical Oncology, Peter MacCallum Cancer Centre, St Andrews Place, East Melbourne, Victoria 3002, Australia; \\ ${ }^{3}$ Department of Pharmacy, Peter MacCallum Cancer Centre, St Andrews Place, East Melbourne, Victoria 3002, Australia; ${ }^{4}$ Department of Pharmacy \\ Practice, Victorian College of Pharmacy, Monash University, Royal Parade, Parkville, Victoria 3052, Australia
}

Pneumocystis jirovecii pneumonia (PCP) is associated with high mortality in immunocompromised patients without human immunodeficiency virus infection. However, chemoprophylaxis is highly effective. In patients with solid tumours or haematologic malignancy, several risk factors for developing PCP have been identified, predominantly corticosteroid therapy. The aims of this study were to identify the potentially preventable cases of PCP in patients receiving corticosteroid therapy at a tertiary care cancer centre and to estimate the frequency of utilisation of chemoprophylaxis in these patients. Two retrospective reviews were performed. Over a 10-year period, 14 cases of PCP were identified: no cases were attributable to failed chemoprophylaxis, drug allergy or intolerance. During a 6-month period, 73 patients received high-dose corticosteroid therapy ( $\geqslant 25 \mathrm{mg}$ prednisolone or $\geqslant 4$ mg dexamethasone daily) for $\geqslant 4$ weeks. Of these, 22 (30\%) had haematologic malignancy, and 5 I (70\%) had solid tumours. Fewer patients with solid tumours received prophylaxis compared to patients with haematologic malignancy (3.9 vs $63.6 \%, P<0.000$ I). Guidelines for PCP chemoprophylaxis in patients with haematologic malignancy or solid tumours who receive corticosteroid therapy are proposed. Successful primary prevention of PCP in this population will require a multifaceted approach targeting the suboptimal prescribing patterns for chemoprophylaxis.

British Journal of Cancer (2005) 92, 867-872. doi: 10.1038/sj.bjc.66024I2 www.bjcancer.com

Published online 22 February 2005

(c) 2005 Cancer Research UK

Keywords: Pneumocystis pneumonia; chemoprophylaxis; malignancy; corticosteroid; guidelines

Pneumocystis jirovecii pneumonia (PCP) is a potentially lifethreatening opportunistic infection seen predominantly in immunosuppressed individuals, and with increasing frequency in human immunodeficiency (HIV)-negative patients. The case fatality rate among HIV-negative patients with PCP has remained approximately $50 \%$ over the last three decades (Walzer et al, 1974; Sepkowitz et al, 1992; Sepkowitz, 2002), despite identification of risk factors, including malignancy (Sepkowitz et al, 1992; Zahar et al, 2002), haematologic disorders (Sepkowitz et al, 1992), radiation therapy (Mathew and Grossman, 2003), chemotherapy (Hughes et al, 1975; Sepkowitz et al, 1992), organ transplantation (Hardy et al, 1984; Sepkowitz et al, 1995) and CD4 ${ }^{+}$lymphopenia (Mansharamani et al, 2000). In patients with solid tumours or haematologic malignancy, corticosteroid therapy is the most common predisposing risk factor for developing PCP (Sepkowitz et al, 1992; Sepkowitz, 1993; Yale and Limper, 1996).

\footnotetext{
*Correspondence: Dr LJ Worth, Department of Infectious Diseases, Peter MacCallum Cancer Centre, St Andrews Place, East Melbourne, Victoria 3002, Australia; E-mail: leon.worth@petermac.org

Received 3I August 2004; revised 9 December 2004; accepted 5 January 2005; published online 22 February 2005
}

Identifying patients who are at risk of PCP is important, as highly effective prophylactic strategies are available. Risk assessment based on intensity of corticosteroid therapy is possible as dose, duration and tapering of corticosteroid therapy appear to impact upon the risk for development of PCP (Sepkowitz et al, 1992; Slivka et al, 1993; Sepkowitz, 1996; Yale and Limper, 1996). In a study of 116 HIV-negative patients with PCP, the median daily dose of corticosteroid was equivalent to $30 \mathrm{mg}$ prednisolone, and the median duration of therapy before the onset of infection was 12 weeks (Yale and Limper, 1996). Sepkowitz et al have recommended that any patient with an underlying immunologic disorder (including malignancy) who receives the equivalent of at least $20 \mathrm{mg}$ of prednisolone daily for more than 1 month be given prophylaxis (Sepkowitz et al, 1995; Sepkowitz, 1996).

The Peter MacCallum Cancer Centre (PMCC) is a tertiary care cancer centre which sees the full spectrum of malignant disorders. Since 1999, guidelines for trimethoprim-sulphamethoxazole (TMP-SMX) prophylaxis have been utilised in patients receiving selected high-intensity chemotherapy protocols: hyper-CVAD (Kantarjian et al, 2000), VAD (Barlogie et al, 1984), CEVAD (Giles et $a l, 2000$ ) and FLAG (Estey et al, 1994). Adherence to the guidelines and frequency of chemoprophylaxis in other patients with haematological malignancy or solid tumours is unknown. 
The aims of this study were to (1) identify the potentially preventable cases of PCP, and (2) estimate the proportional use of suitable chemoprophylaxis in patients at risk for PCP on the basis of corticosteroid therapy. Finally, we propose a strategy for PCP prophylaxis in patients with haematological malignancy or solid tumours, who receive high-dose corticosteroid therapy.

\section{MATERIALS AND METHODS}

To study the relationship between use of prophylaxis and development of PCP, a retrospective case series of all confirmed cases of PCP treated at PMCC between 1994 and 2003 was performed. The proportion of at-risk patients receiving prophylaxis was estimated by a retrospective review of hospital pharmacy records, identifying the use of prophylaxis in patients receiving corticosteroid therapy during a 6-month period (2003).

\section{Pneumocystis jirovecii pneumonia cases}

All patients with a discharge diagnosis of PCP from 1/1/1994 to 31/ $12 / 2003$ were identified by ICD9-CM or ICD10-AM code. A case was defined as a patient with morphologic evidence of Pneumocystis by toluidine blue staining and/or direct fluorescent antigen detection in a respiratory specimen (sputum, induced sputum or bronchoscopy specimen). Corticosteroid therapy was defined as administration of prednisolone, dexamethasone, hydrocortisone or methylprednisolone in addition to any chemotherapeutic regimen containing dexamethasone or prednisolone components. Only cases receiving corticosteroid therapy prior to onset of PCP were studied.

Charts were reviewed, and demographic details, clinical findings, predisposing factors and treatment outcome established for each case. Dose of corticosteroid, duration of therapy prior to onset of symptoms and tapering of doses were determined. Other possible risk factors for PCP were analysed: radiation therapy, chemotherapy and stem cell transplantation. Use of prophylaxis (TMP-SMX, dapsone, pentamidine), and potential reasons for lack of prophylaxis (previous drug allergy or intolerance, patient not considered high risk by treating physician, patient requiring palliative care services, noncompliance) were documented.

\section{Prophylaxis in at-risk patients}

Pharmacy records for a 6-month period (1/6/03-30/11/03) were used to identify patients at PMCC who were at risk for development of PCP on the basis of steroid therapy and underlying malignancy. At-risk cases were defined as patients who were dispensed with $\geqslant 25 \mathrm{mg}$ prednisolone or $\geqslant 4 \mathrm{mg}$ dexamethasone daily for $\geqslant 4$ weeks. Chart review was performed to determine the demographic details and to identify concurrent use of PCP prophylaxis (as defined above).

\section{Statistical analysis}

Statistical comparison of patients with haematologic malignancy and solid tumours was carried out by the $\chi^{2}$-test, with $P<0.05$ deemed significant.

\section{RESULTS}

\section{Pneumocystis jirovecii pneumonia cases}

Out of 60 patients identified with a discharge diagnosis of PCP, 35 were excluded because no microbiological confirmation of PCP was made. Of the remaining 25 patients with confirmed PCP, 11 had no corticosteroid therapy administered prior to onset of PCP. Two of these had solid tumours (colorectal adenocarcinoma, anaplastic thyroid carcinoma) and nine patients had haematological malignancy (AML (three), non-Hodgkin's lymphoma (two), Hodgkin's disease (two), CLL (two)). In the subgroup with haematological malignancy, a number of predisposing factors were identified: external beam radiation (three), autologous stem cell transplantation (two), and chemotherapy with fludarabine (four), cyclophosphamide (three), cytarabine (three) and methotrexate (one). $P$. jirovecii pneumonia was the cause of death in three out of 11 cases.

Of the 14 patients who received steroid therapy prior to onset of microbiologically confirmed PCP, incomplete data were available for one patient (steroid therapy commenced prior to transfer from another institution). This patient was not included in analysis. Among the 13 analysed cases, the mean age was 56 years (eight males, five females). Table 1 summarises the underlying malignancy and corticosteroid therapy in cases. The median duration of corticosteroid therapy prior to onset of PCP was 35 days (range $18-92)$, and four cases (31\%) were receiving tapering doses at diagnosis of PCP. There were no cases due to failed prophylaxis (no case received prophylaxis prior to onset of PCP), documented drug allergy or intolerance precluding consideration of prophylaxis. One case was receiving palliative care services prior to onset of PCP symptoms. Mortality attributed to PCP was $8 \%$.

\section{Prophylaxis in at-risk patients}

In all, 73 patients receiving corticosteroid therapy of sufficient dose and duration were identified during the defined 6-month period. Of these, $22(30 \%)$ had haematological malignancy and 51 (70\%) had solid tumours. Table 2 lists the frequency of diseases in these populations. Figure 1 shows all patients who received $\geqslant 25 \mathrm{mg}$ prednisolone or $\geqslant 4 \mathrm{mg}$ dexamethasone daily for $\geqslant 4$ weeks, and the proportion who were also administered PCP prophylaxis. Significantly fewer at-risk patients with solid tumours received prophylaxis compared to patients with haematologic malignancy (3.9 vs 63.6\%, $P<0.0001$ ).

During this 6-month period, one case of PCP occurred in a patient not receiving chemoprophylaxis. Using the number of patients receiving corticosteroid therapy without PCP chemoprophylaxis as the denominator (57 patients in 6 months), the estimated crude incidence is 18 PCP cases per 1000 patients with malignancy receiving corticosteroid therapy for $\geqslant 4$ weeks.

\section{DISCUSSION}

Our study focused on PCP prophylaxis in patients receiving corticosteroid therapy for solid tumours or haematologic malignancy. Although the mechanisms of immune compromise in this population are multifactorial, corticosteroid therapy is a significant and readily identifiable risk factor, providing opportunity for modification of prescribing practices relevant to prophylaxis.

We have identified differences in proportion of patients with solid tumours receiving chemoprophylaxis compared to patients with haematologic malignancy. This may be attributed to the use of prescriber guidelines within some groups of haematology patients at PMCC. However, even in this group, a large proportion (36.4\%) were not prescribed chemoprophylaxis, and the observed number of cases of PCP (seven out of 13) in haematology patients would suggest significant under-prescribing. Our estimation of incidence of PCP is based upon a number of assumptions, including consistency of hospital bed-days, indications for corticosteroid therapy, and proportion of solid and haematological malignancy treated at PMCC during the study period. Communitybased prescription of corticosteroid therapy was not captured, leading to possible overestimation of incidence.

In our series, predisposing corticosteroid therapy was not administered in 11 patients with PCP. Only two cases had solid 
Table I Cases of PCP in patients receiving corticosteroid therapy, PMCC I///1994-31//2/2003

\begin{tabular}{|c|c|c|c|c|c|c|c|c|}
\hline \multirow[b]{2}{*}{ Age/sex } & \multirow[b]{2}{*}{ Malignancy } & \multicolumn{3}{|c|}{ Corticosteroid $^{\mathrm{a}}$} & \multicolumn{4}{|c|}{ Other risk factors for PCP } \\
\hline & & Dose & $\begin{array}{c}\text { No. } \\
\text { of } \\
\text { days }\end{array}$ & Tapering & Transplantation & $\begin{array}{l}\text { Cytotoxic } \\
\text { therapy }\end{array}$ & $\begin{array}{l}\text { External } \\
\text { beam } \\
\text { radiation }\end{array}$ & Outcome \\
\hline \multicolumn{9}{|c|}{ Solid tumours } \\
\hline $57 / M$ & Thyroid carcinoma & DXM $16 \mathrm{mg}$ & 30 & Y & $\mathrm{N}$ & Radioactive iodine & $\mathrm{N}$ & Resolved \\
\hline $63 / M$ & GBM & DXM $16 \mathrm{mg}$ & 34 & $\mathrm{~N}$ & $\mathrm{~N}$ & $\mathrm{~N}$ & $\mathrm{~N}$ & Resolved \\
\hline $36 / F$ & Breast carcinoma & PNL 25 mg & 40 & $\mathrm{~N}$ & Autologous HSCT & EC & Y & Resolved \\
\hline $65 / M$ & NSCLC & DXM $16 \mathrm{mg}$ & 88 & Y & $\mathrm{N}$ & Gemcitabine & Y & Resolved \\
\hline \multicolumn{9}{|c|}{ Haematologic malignancy } \\
\hline $44 / F$ & $\mathrm{NHL}$ & PNL $100 \mathrm{mg}$ & 50 & $\mathrm{~N}$ & $\mathrm{~N}$ & $\mathrm{CHOP}$ & Y & Resolved \\
\hline $71 / M$ & AML & PNL 25 mg & 45 & $\mathrm{~N}$ & $\mathrm{~N}$ & FLAG, hydroxyurea & Y & Resolved \\
\hline $61 / F$ & $\mathrm{NHL}$ & DXM $16 \mathrm{mg}$ & 35 & Y & $N$ & CHOP, Mabthera, RICE & $\mathrm{N}$ & Resolved \\
\hline
\end{tabular}

anitial daily dose and number of days of corticosteroid therapy prior to onset of PCP symptoms; DXM= dexamethasone; PNL = prednisolone. ${ }^{\text {bPatient }}$ commenced corticosteroid therapy at another institution prior to transfer. $G B M=$ glioblastoma multiforme; $N H L=$ non-Hodgkin's lymphoma; $A M L=$ acute myeloid leukaemia; $\mathrm{CML}=$ chronic myeloid leukaemia; $\mathrm{EC}=$ epirubicin, cyclophosphamide; $\mathrm{CHOP}=$ cyclophosphamide, doxorubicin, oncovin, prednisolone; FLAG = fludarabine, cytarabine, $\mathrm{G}-$ CSF; RICE = rituximab, ifosfamide, carboplatin, etoposide; $M T X=$ methotrexate; Ara- $C=$ cytarabine; IFN=interferon $\alpha-2 b ; P C A B=$ prednisolone, cyclophosphamide, doxorubicin, carmustine; $\mathrm{VAD}=$ vincristine, doxorubicin, dexamethasone; HSCT = haematopoietic stem cell transplantation.

Table 2 At-risk patients receiving high-dose corticosteroid therapy, PMCC 1/6/03-30/11/03

\begin{tabular}{lr}
\hline Malignancy & $\mathbf{n}$ \\
\hline Solid tumours & \\
Lung (non-small cell) & 13 \\
Genitourinary & 9 \\
Breast & 8 \\
Gastrointestinal & 7 \\
Melanoma & 4 \\
Adenocarcinoma, unknown primary & 4 \\
Central nervous system (primary) & 2 \\
Sarcoma & 2 \\
Adenoid cystic carcinoma & I \\
Parotid & 1 \\
& \\
Haematologic malignancy & 14 \\
Multiple myeloma & 6 \\
Non-Hodgkin's lymphoma & 2 \\
Chronic lymphocytic leukaemia & \\
Total & 73 \\
\hline
\end{tabular}

tumours, suggesting that the vast majority of at-risk patients with solid tumours can be identified on the basis of corticosteroid therapy. Nine cases had haematological malignancy. Given the heterogeneity of potential risk factors in this subgroup, distinct recommendations for prophylaxis must be based upon the underlying disease or predisposing chemotherapy. For example, chemoprophylaxis should be administered for 6 months following engraftment in allogeneic transplant recipients (Dykewicz, 2001). This may be extended where immunosuppressive therapy or chronic GVHD persists beyond 6 months. Chemoprophylaxis should be considered in autologous stem cell transplant recipients with underlying lymphoma or leukaemia, intense conditioning regimens, or recently administered fludarabine or 2-chlorodeoxyadenosine (Rodriguez and Fishman, 2004). Patients receiving alemtuzumab therapy should receive PCP chemoprophylaxis for at least 2 months after therapy (Keating et al, 2004).

\section{Trimethoprim - sulfamethoxazole prophylaxis}

Pneumocystis jirovecii pneumonia prophylaxis is effective in patients not infected with HIV. Munoz et al (1997) showed that TMP - SMX (administered on weekends only) eliminated all cases of PCP in a population of heart transplant recipients, compared to $4 \%$ incidence prior to prophylaxis. TMP - SMX has been shown to be an effective prophylaxis in patients with cancer (Hughes et al, 1977). Daily and thrice weekly dosing regimens have demonstrated equivalence in patients with leukaemia (Hughes et al, 1987; Rossi et al, 1987), and twice weekly dosing has been shown to be effective in allogeneic transplant recipients (Souza et al, 1999).

\section{Precautions and contraindications}

Contraindications to the TMP-SMX prophylaxis must be considered: documented hypersensitivity, megaloblastic anaemia due to folate deficiency, severe renal impairment and porphyria (Masters et al, 2003). Caution must also be exercised in patients with impaired renal function, impaired hepatic function, severe drug allergies, glucose-6-phosphate dehydrogenase deficiency or blood dyscrasias. The potential for myelosuppression or drug interactions may necessitate consideration of an alternative prophylactic agent.

Myelosuppression has been associated with TMP-SMX use in children with acute lymphoblastic leukaemia (Woods et al, 1984). Conversely, in a study of adult patients with acute leukaemia, no significant difference in myelosuppression was found when TMP SMX (1 double strength tablet twice daily) was compared with placebo (Ward et al, 1993). The original reports of efficacy of TMP-SMX for prophylaxis did not demonstrate significant 


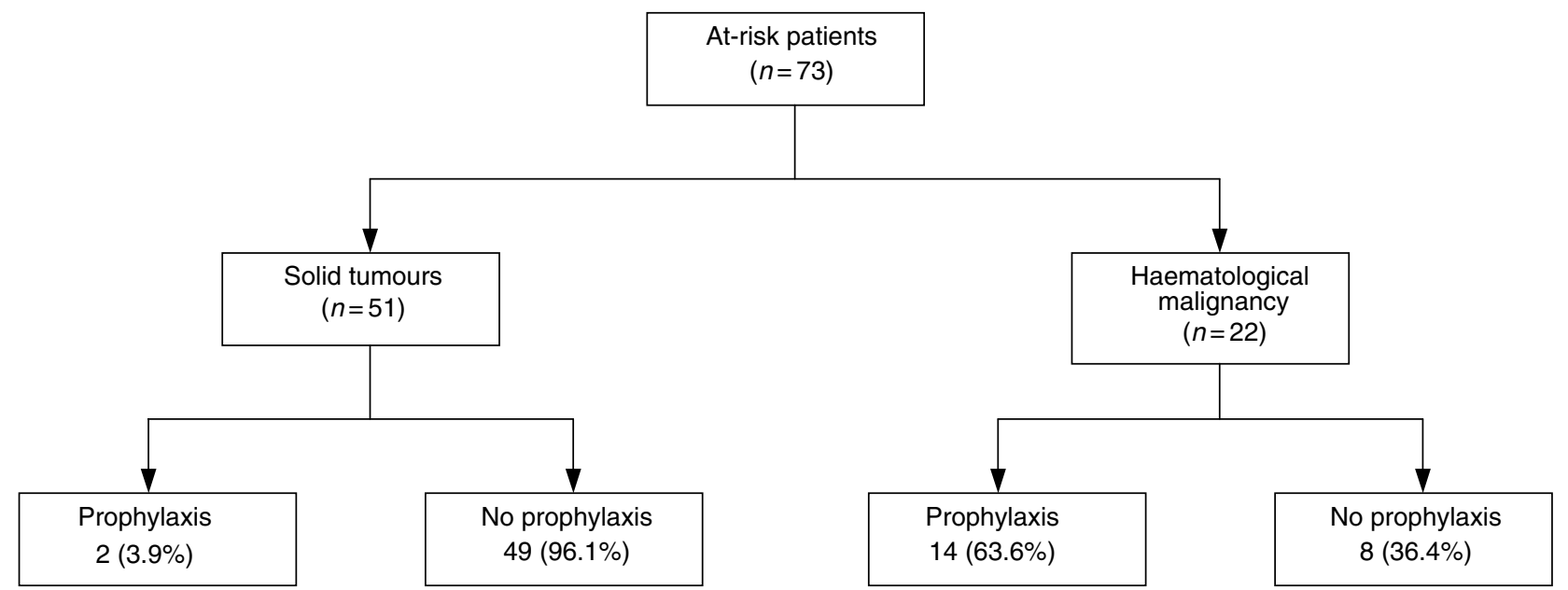

Figure I Pneumocystis jirovecii pneumonia prophylaxis in at-risk patients receiving corticosteroid therapy, PMCC I/6/03-30/I I/03.

Table 3 Guidelines: PCP prophylaxis for patients with malignancy who receive corticosteroid therapy

Chemoprophylaxis for Pneumocystis jirovecii pneumonia should be administered when treatment with $\geqslant 20 \mathrm{mg}$ prednisolone equivalents for $\geqslant 1$ month is planned.

First-line prophylactic agent should be trimethoprim-sulphamethoxazole (one DS ablet daily, one DS tablet three times weekly or two DS tablets twice weekly), unless:

(i) Myelosuppression due to chemotherapy or radiation likely to be present for $>7$ days Recommend: second-line prophylactic agent

(ii) Previous allergy or hypersensitivity to sulpha-drugs Recommend: trimethoprim-sulphamethoxazole desensitisation (unless previous anaphylaxis)

(iii) Planned methotrexate chemotherapy Recommend: second-line prophylactic agent.

A second-line prophylactic agent should be used if trimethoprim-sulphamethoxazole is contraindicated:

(i) Dapsone (100 mg daily), OR

(ii) Pentamidine ${ }^{b}$ (nebulised, 300 mg monthly), OR

(iii) Atovaquone ( $1500 \mathrm{mg}$ daily).

Prophylaxis should continue until at least I month after steroid cessation. A longer period of prophylaxis may be required if ongoing chemotherapy (e.g. cytarabine, cyclophosphamide, fludarabine, fluorouracil, methotrexate) is planned. Life-long prophylaxis should be considered if the patient has had a previous episode of PCP and persisting immunosuppression.

${ }^{a} \mathrm{DS}=$ double strength; trimethoprim $160 \mathrm{mg}$ per $800 \mathrm{mg}$ sulphamethoxazole. ${ }^{\mathrm{b}}$ Screening antibodies for $T$. gondii should be checked prior to use following bone marrow transplantation. 'No studies of efficacy in patients with malignancy.

myelosuppression (Hughes et al, 1977, 1987). However, when used for prophylaxis against bacteraemia following autologous bone marrow transplantation, the time to neutrophil recovery is significantly longer in patients receiving TMP-SMX, compared to patients receiving ciprofloxacin (Imrie et al, 1995). We recommend that an alternative prophylactic agent be used in at-risk patients with expected myelosuppression $>7$ days (Table 3).

In patients receiving chemotherapy with methotrexate, pancytopenia may occur if prophylactic TMP-SMX is used concurrently. The sulphamethoxazole component may increase toxicity of methotrexate by displacement from binding sites or reduced renal excretion (Masters et al, 2003; Mathew and Grossman, 2003). Small studies of children with acute leukaemia have demonstrated both increased free methotrexate (Ferrazzini et al, 1990) and no change in plasma concentration of methotrexate (Beach et al, 1981) when co-administered with TMP-SMX. In a study of patients with rheumatoid arthritis treated with up to $25 \mathrm{mg}$ methotrexate per week who received TMP-SMX prophylaxis, no patient developed myelosuppression (Langford et al, 2003). Conversely, there are a number of case reports of significant adverse events with the combination (Groenendal and Rampen, 1990; Govert et al, 1992; Steuer and Gumpel, 1998; Saravana and Lalukotta, 2003). We therefore recommend an alternative prophylactic agent in the setting of concurrent methotrexate therapy (Table 3).

Prophylaxis with TMP-SMX may not be tolerated in patients with advanced malignancy and reduced oral intake due to nausea or dysphagia. This may not have been a significant contributor to duration of prophylaxis in our series as only one out of 13 cases of PCP were utilising palliative care services at the time of diagnosis. Further study is required to address the question of appropriateness of commencing prophylaxis in the setting of palliation.

\section{Alternative agents}

As demonstrated in HIV-infected patients (Martin et al, 1993; Warnock and Rimland, 1996; El-Sadr et al, 1998), alternative prophylactic agents may be used, but are associated with higher rates of failure. Dapsone prophylaxis (50 mg three times per week) in allogeneic transplant recipients has a significantly higher incidence of failure when compared to TMP-SMX (Souza et al, 1999). Aerosolised pentamidine ( $150 \mathrm{mg}$ every 2 weeks or $300 \mathrm{mg}$ per month) used after bone marrow transplantation has been shown to be inferior to TMP-SMX for PCP prophylaxis (Vasconcelles et al, 2000) and associated with an increased risk 
for developing toxoplasmosis in immunocompromised patients with antibodies to Toxoplasma gondii (Machado et al, 1998). Safety and tolerability of atovaquone prophylaxis ( $1500 \mathrm{mg}$ daily) has been demonstrated in autologous stem cell transplant recipients (Colby et al, 1999), but studies of efficacy in non-HIV-infected patients are lacking. Use of clindamycin ( $300 \mathrm{mg}$ daily) and primaquine (15 mg daily) for prophylaxis in HIV-infected patients is associated with a higher risk for developing PCP than the TMP SMX prophylaxis (Barber et al, 1996). Efficacy of clindamycin/ primaquine for prophylaxis in patients with malignancy has not been reported.

Due to ease of administration and medical costs, we recommend that dapsone be used as second-line prophylaxis if TMP-SMX is contraindicated or not tolerated (Table 3). Nebulised pentamidine may also be used, and atovaquone may be considered in patients unable to tolerate TMP-SMX or dapsone.

\section{Duration of prophylaxis}

Although some have recommended that prophylaxis continue for 1 month after discontinuation of corticosteroids (Sepkowitz, 2002), extended duration may be required with other concurrently administered immunosuppressive therapies. For example, cytarabine (Hughes et al, 1975), cyclophosphamide (Kulke and Vance, 1997), methotrexate (Kane et al, 1993), fluorouracil (Hardy et al, 1987) and fludarabine (Bastion et al, 1991) have all been associated with development of PCP in the absence of corticosteroid treatment, although the absolute risk is unclear. We recommend continued primary prophylaxis or lifelong secondary prophylaxis in the setting of ongoing immunosuppression (Table 3).

\section{REFERENCES}

Auperin A, Chouaid C, des Fontaines VH (1994) Attitudes to prevention among HIV-infected patients: the case of specific prophylaxis for Pneumocystis carinii pneumonia. Health Policy 27: 253-259

Barber BA, Pegram PS, High KP (1996) Clindamycin/primaquine as prophylaxis for Pneumocystis carinii pneumonia. Clin Infect Dis 23: $718-722$

Barlogie B, Smith L, Alexanian R (1984) Effective treatment of advanced multiple myeloma refractory to alkylating agents. $N$ Engl J Med 310: $1353-1356$

Bastion Y, Coiffier B, Tigaud JD, Espinouse D, Byron PA (1991) Pneumocystis pneumonia in a patient treated with fludarabine for chronic lymphocytic leukemia. Eur J Cancer 27: 671

Beach BJ, Woods WG, Howell SB (1981) Influence of co-trimoxazole on methotrexate pharmacokinetics in children with acute lymphoblastic leukemia. Am J Pediatr Haematol Oncol 3: 115-119

Colby C, McAfee SL, Sackstein R, Finkelstein DM, Fishman JA, Spitzer TR (1999) A prospective randomized trial comparing the toxicity and safety of atovaquone with trimethoprim/sulfamethoxazole as Pneumocystis carinii pneumonia prophylaxis following autologous peripheral blood stem cell transplantation. Bone Marrow Transplant 24: 897-902

Dykewicz CA, Centers for Disease Control and Prevention (US); Infectious Diseases Society of America; American Society of Blood and Marrow Transplantation (2001) Summary of the guidelines for preventing opportunistic infections among hematopoietic stem cell transplant recipients. Clin Infect Dis 33: 139-144

El-Sadr WM, Murphy RL, Yurik TM, Luskin-Hawk R, Cheung TW, Balfour HH, Eng R, Hooton TM, Kerkering TM, Schutz M, van der Horst C, Hafner C (1998) Atovaquone compared with dapsone for the prevention of Pneumocystis carinii pneumonia in patients with HIV infection who cannot tolerate trimethoprim, sulfonamides, or both. $N$ Engl J Med 339: 1889 - 1895

Estey E, Thall P, Andreeff M, Beran M, Kantarjian H, O’Brien S, Escudier S, Robertson LE, Koller C, Kornblau S, Pierce S, Freireich EJ, Deisseroth A, Keating M (1994) Use of granulocyte colony-stimulating factor before, during, and after fludarabine plus cytarabine induction therapy of newly diagnosed acute myelogenous leukemia or myelodysplastic syndromes:

\section{Improving utilisation and prescriber practices}

Suboptimal prescribing patterns for PCP chemoprophylaxis have been described in HIV-infected patients (Montaner et al, 1996; Schwarcz et al, 1997). Reasons are multifactorial, including patient reluctance or inability to access healthcare services (Schwarcz et al, 1997), and failure of a treating clinician to identify the need for prophylaxis (Auperin et al, 1994). In our patient population, it appears that prescriber factors are a greater barrier to PCP prophylaxis than poor access to healthcare, as no case of noncompliance was identified in the series of PCP cases, and patients were otherwise attending the regular review for treatment of underlying malignancy.

We have formulated guidelines for PCP chemoprophylaxis in patients receiving corticosteroid therapy for malignancy (Table 3). If applied to the cases of PCP observed at PMCC, 11 out of 13 cases $(85 \%)$ could potentially have been prevented. Successful primary prevention of PCP in this population will require a multifaceted approach including academic detailing (one-on-one education of clinicians and hospital pharmacists). This has previously been successfully implemented to enhance the use of preventive medication for corticosteroid-induced osteoporosis (Naunton et al, 2004). Novel strategies, such as generation of computerised clinical reminders (Kralj et al, 2003) from pharmacy records of dispensed corticosteroid, should also be considered.

\section{ACKNOWLEDGEMENTS}

We are grateful to Sandy Scholes for the review of pharmacy dispensing records. comparison with fludarabine plus cytarabine without granulocyte colony-stimulating factor. J Clin Oncol 12: 671-678

Ferrazzini G, Klein J, Sulh H, Chung D, Griesbrecht E, Koren G (1990) Interaction between trimethoprim-sulfamethoxazole and methotrexate in children with leukemia. J Pediatr 117: 823-826

Giles FJ, Wickham NR, Rapoport BL, Somio G, Lim SW, Shan J, Lynott AM (2000) Cyclophosphamide, etoposide, vincristine, Adriamycin, and dexamethasone (CEVAD) regimen in refractory multiple myeloma: an International Oncology Study Group (IOSG) phase II protocol. Am J Hematol 63: $125-130$

Govert JA, Patton S, Fine RL (1992) Pancytopenia from using trimethoprim and methotrexate. Ann Intern Med 117: 877 - 878

Groenendal H, Rampen FH (1990) Methotrexate and trimethoprimsulphamethoxazole - a potentially hazardous combination. Clin Exp Dermatol 15: $358-360$

Hardy AM, Wajszczuk CP, Suffredini AF, Hakala TR, Ho M (1984) Pneumocystis carinii pneumonia in renal transplant patients treated with cyclosporine and steroids. J Infect Dis 149: $143-147$

Hardy R, Cummings C, Faulkner M, Obianyo I (1987) Pneumocystis carinii pneumonia following 5-fluorouracil administration. J Natl Med Assoc 79: $1205-1209$

Hughes WT, Feldman S, Aur RJ, Verzosa MS, Hustu HO, Simone JV (1975) Intensity of immunosuppressive therapy and the incidence of Pneumocystis carinii pneumonitis. Cancer 36: 2004-2009

Hughes WT, Kuhn S, Chaudhary S, Feldman S, Verzosa M, Aur RJ, Pratt C, George SL (1977) Successful chemoprophylaxis for Pneumocystis carinii pneumonitis. $N$ Engl J Med 297: 1419-1426

Hughes WT, Rivera GK, Schell MJ, Thornton D, Lott L (1987) Successful intermittent chemoprophylaxis for Pneumocystis carinii pneumonitis. $N$ Engl J Med 316: 1627-1632

Imrie KR, Prince HM, Couture F, Brandwein JM, Keating A (1995) Effect of antimicrobial prophylaxis on hematopoietic recovery following autologous bone marrow transplantation: ciprofloxacin versus co-trimoxazole. Bone Marrow Transplant 15: $267-270$

Kane GC, Israel HL, Peters SP (1993) Pneumocystis carinii pneumonia and methotrexate therapy. Chest 103: 1923 
Kantarjian HM, O'Brien S, Smith TL, Cortes J, Giles FJ, Beran M, Pierce S, Huh Y, Andreeff M, Koller C, Ha CS, Keating MJ, Murphy S, Freireich EJ (2000) Results of treatment with hyper-CVAD, a dose-intensive regimen, in adult acute lymphocytic leukemia. J Clin Oncol 18: 547-561

Keating M, Coutre S, Rai K, Osterborg A, Faderl S, Kennedy B, Kipps T, Bodey G, Byrd JC, Rosen S, Dearden C, Dyer MJ, Hillmen P (2004) Management guidelines for use of alemtuzumab in B-cell chronic lymphocytic leukemia. Clin Lymphoma 4: 220-227

Kralj B, Iverson D, Hotz K, Ashbury FD (2003) The impact of computerized clinical reminders on physician prescribing behaviour: evidence from community oncology practice. Am J Med Qual 18: 197-203

Kulke MH, Vance EA (1997) Pneumocystis carinii pneumonia in patients receiving chemotherapy for breast cancer. Clin Infect Dis 25: 215-218

Langford CA, Talar-Williams C, Barron KS, Sneller MC (2003) Use of a cyclophosphamide-induction methotrexate-maintenance regimen for the treatment of Wegener's granulomatosis: extended follow-up and rate of relapse. Am J Med 114: 463-469

Machado CM, Macedo MCA, Medeiros RSS, Massumoto C, Silva ACM, Castelli JB, Silva RL, Ostronoff M, Dulley FL (1998) Primary Pneumocystis carinii prophylaxis with aerosolized pentamidine after bone marrow transplantation. Acta Haematol 99: 54-56

Mansharamani NG, Balachandran D, Verovsky I, Garland R, Koziel H (2000) Peripheral blood CD4+ T-lymphocyte counts during Pneumocystis carinii pneumonia in immunocompromised patients without HIV infection. Chest 118: 712-720

Martin MA, Cox PH, Beck K, Styer CM, Beall GN (1993) A comparison of the effectiveness of three regimens in the prevention of Pneumocystis carinii pneumonia in human immunodeficiency virus-infected patients. Arch Intern Med 153: $782-783$

Masters PA, O'Bryan TA, Zurlo J, Miller DQ, Joshi N (2003) Trimethoprim - sulfamethoxazole revisited. Arch Intern Med 163: 402-410

Mathew BS, Grossman SA (2003) Pneumocystis carinii pneumonia prophylaxis in HIV negative patients with primary CNS lymphoma. Cancer Treat Rev 29: 105-119

Montaner JS, Phillips P, Zala C, Craib KJ, O'Shaughnessy MV, Schechter MT (1996) Adherence to guidelines for prevention of HIV-related respiratory disease. Eur Respir J 9: 2318-2322

Munoz P, Munoz RM, Palomo J, Rodriguez-Creixems M, Munoz R, Bouza E (1997) Pneumocystis carinii infection in heart transplant recipients: efficacy of a weekend prophylaxis schedule. Medicine (Baltimore) 76: $415-422$

Naunton M, Peterson GM, Jones G, Griffin GM, Bleasel MD (2004) Multifaceted educational program increases prescribing of preventive medication for corticosteroid induced osteoporosis. J Rheumatol 31: $550-556$

Rodriguez M, Fishman JA (2004) Prevention of infection due to Pneumocystis spp. in human immunodeficiency virus-negative immunocompromised patients. Clin Microbiol Rev 17: 770-782

Rossi MR, Banfi P, Cuppuccilli M, Conter V, de Poli D, Piacentini G, Zurlo MG, Masera G (1987) Prospective randomized comparison of two prophylactic regimens with trimethoprim - sulfamethoxazole in leukemic children: a two year study. Eur J Cancer Clin Oncol 23: 1679-1682

Saravana S, Lalukotta K (2003) Myelotoxicity due to methotrexate - an iatrogenic cause. Eur J Haematol 71: 315-316
Schwarcz SK, Katz MH, Hirozawa A, Gurley J, Lemp GF (1997) Prevention of Pneumocystis carinii pneumonia: who are we missing? AIDS 11: 1263 1268

Sepkowitz KA (1993) Pneumocystis carinii pneumonia in patients without AIDS. Clin Infect Dis 17(Suppl 2): S416-S422

Sepkowitz KA (1996) Pneumocystis carinii pneumonia without acquired immunodeficiency syndrome: who should receive prophylaxis? Mayo Clin Proc 71: $102-103$

Sepkowitz KA (2002) Opportunistic infections in patients with and patients without acquired immunodeficiency syndrome. Clin Infect Dis 34: 1098 1107

Sepkowitz KA, Brown AE, Armstrong D (1995) Pneumocystis carinii pneumonia without acquired immunodeficiency syndrome: more patients, same risk. Arch Intern Med 155: 1125-1128

Sepkowitz KA, Brown AE, Telzak EE, Gottileb S, Armstrong D (1992) Pneumocystis carinii pneumonia among patients without AIDS at a cancer hospital. JAMA 267: $832-837$

Slivka A, Wen PY, Shea WM, Loeffler JS (1993) Pneumocystis carini pneumonia during steroid taper in patients with primary brain tumors. Am J Med 94: 216-219

Souza JP, Boeckh M, Gooley TA, Flowers ME, Crawford SW (1999) High rates of Pneumocystis carinii pneumonia in allogeneic blood and marrow transplant recipients receiving dapsone prophylaxis. Clin Infect Dis 29: $1467-1471$

Steuer A, Gumpel JM (1998) Methotrexate and trimethoprim: a fatal interaction. Br J Rheumatol 37: 105-106

Vasconcelles MJ, Bernardo MV, King C, Weller EA, Antin JH (2000) Aerosolized pentamidine as pneumocystis prophylaxis after bone marrow transplantation is inferior to other regimens and is associated with decreased survival and an increased risk of other infections. Biol Blood Marrow Transplant 6: 35-43

Walzer PD, Perl DP, Krogstad DJ, Rawson PG, Schultz MG (1974) Pneumocystis carinii pneumonia in the United States: epidemiologic, diagnostic, and clinical features. Ann Intern Med 80: 83-93

Ward TT, Thomas RG, Fye CL, Arbeit R, Coltman Jr CA, Craig W, Dana BW, Finegold SM, Lentino J, Penn RL, Weinberg JB, Chow B, Ochi S (1993) Trimethoprim-sulfamethoxazole prophylaxis in granulocytopenic patients with acute leukemia: evaluation of serum antibiotic levels in a randomized, double-blind, placebo-controlled Department of Veterans Affairs Cooperative Study. Clin Infect Dis 17: $323-332$

Warnock AC, Rimland D (1996) Comparison of trimethoprim-sulfamethoxazole, dapsone, and pentamidine in the prophylaxis of Pneumocystis carinii pneumonia. Pharmacotherapy 16: 1030-1038

Woods WG, Daigle AE, Hutchinson RJ, Robinson LL (1984) Myelosuppression associated with co-trimoxazole as a prophylactic antibiotic in the maintenance phase of a childhood acute lymphocytic leukemia. J Pediat 105: $639-644$

Yale SH, Limper AH (1996) Pneumocystis carinii pneumonia in patients without acquired immunodeficiency syndrome: associated illnesses and prior corticosteroid therapy. Mayo Clin Proc 71: 5-13

Zahar JR, Robin M, Azoulay E, Fieux F, Nitenberg G, Schlemmer B (2002) Pneumocystis carinii pneumonia in critically ill patients with malignancy: a descriptive study. Clin Infect Dis 35: 929-934 